\title{
Endometriosis - Morphology, Clinical Presentations and Molecular Pathology
}

\author{
Neha Agarwal, Arulselvi Subramanian
}

Department of Laboratory Medicine, Jai Prakash Narayan Apex Trauma centre, AllMS, New Delhi

Address for correspondence: Arulselvi Subramanian, E-mail: drarulselvi@yahoo.co.in

\begin{abstract}
Endometriosis is found predominantly in women of childbearing age. The prevalence of endometriosis is difficult to determine accurately. Laparoscopy or surgery is required for the definitive diagnosis. The most common symptoms are dysmenorrhea, dyspareunia, and low back pain that worsen during menses. Endometriosis occurring shortly after menarche has been frequently reported. Endometriosis has been described in a few cases at the umbilicus, even without prior history of abdominal surgery. It has been described in various atypical sites such as the fallopian tubes, bowel, liver, thorax, and even in the extremities. The most commonly affected areas in decreasing order of frequency in the gastrointestinal tract are the recto-sigmoid colon, appendix, cecum, and distal ileum. The prevalence of appendiceal endometriosis is $2.8 \%$. Malignant transformation is a well-described, although rare $(<1 \%$ of cases), complication of endometriosis. Approximately $75 \%$ of these tumors arise from endometriosis of the ovary. Other less common sites include the rectovaginal septum, rectum, and sigmoid colon. Unopposed estrogens therapy may play a role in the development of such tumors. A more recent survey of 27 malignancies associated with endometriosis found that $17(62 \%)$ were in the ovary, $3(11 \%)$ in the vagina, $2(7 \%)$ each in the fallopian tube or mesosalpinx, pelvic sidewall, and colon, and $1(4 \%)$ in the parametrium. Two cases of cerebral endometriosis and a case of endometriosis presenting as a cystic mass in the cerebellar vermis has been described. Treatment for endometriosis can be expectant, medical, or surgical depending on the severity of symptoms and the patient's desire to maintain or restore fertility.
\end{abstract}

Keywords: Endometriosis, pathogenesis, occurrence

DOI: $10.4103 / 0974-2727.66699$

www.jlponline.org

\section{INTRODUCTION}

6 ndometriosis is described as a benign disease of the female genital system. It is principally characterized by endometrial-like tissue, consisting of glands and/or stroma, found outside the uterine cavity. Although implanted ectopically, this tissue presents histopathological and physiological responses that are similar to the responses of the endometrium. ${ }^{[1]}$ The most common sites affected are the ovaries, uterine ligaments, recto- and vesicovaginal septae, pelvic peritoneum, cervix, labia, and vagina. Malignant transformation of endometriosis may occur in up to $1 \%$ of women, with the most common site being the ovary. ${ }^{[2]}$ The main symptom of endometriosis is pelvic pain, which is often very intense. Dysmenorrhea and other complaints such as dyspareunia and infertility are also seen. ${ }^{[3,4]}$

\section{EPIDEMIOLOGY}

Endometriosis is found predominantly in women of childbearing age. The mean age at diagnosis is 25-29 years, but it is often greater in women who present with infertility rather than pelvic pain. ${ }^{[5]}$ Endometriosis is not uncommon among adolescents. Approximately half of women under 20 years of age who have chronic pelvic pain or dyspareunia have the disease. ${ }^{[6,7]}$ Obstructive müllerian duct anomalies of the cervix or vagina account for most cases of endometriosis in girls under the age of 17 years. ${ }^{[8]}$ About 5\% of endometriosis cases are seen in postmenopausal women, and exogenous estrogen replacement therapy is suggested to play a role. In rare cases, men undergoing long-term estrogen therapy may be affected. ${ }^{[9]}$

The prevalence of endometriosis is difficult to determine accurately. Laparoscopy or surgery is required for the definitive diagnosis. Endometriosis has been reported in $4.1 \%$ of asymptomatic women undergoing laparoscopy for tubal ligation. However, 
in the same study, $20 \%$ of women undergoing laparoscopic investigation for infertility and $24 \%$ of women with pelvic pain had endometriosis ${ }^{[10]}$ The overall prevalence, including both symptomatic and asymptomatic women, is estimated to be $5 \%-10 \% .^{[11,12]}$ The prevalence of endometriosis in infertile women has been reported as 38\% (range 20-40\%).

\section{Etiology of endometriosis}

\section{Theory of retrograde menstruation}

One potential cause of the disease is retrograde menstruation which results in the deposition of endometrial tissue into the peritoneal cavity. Studies in animals have demonstrated that when endometrial cells are deposited in the peritoneal cavity, lesions similar to the endometriotic lesions observed in women develop. ${ }^{[13]}$ The baboon has been used as a model to understand early and progressive events associated with the establishment of the disease. When menstrual effluent is placed in the peritoneum of disease free animals, ectopic lesions develop. Moreover, over time, progressive changes can be observed in both ectopic and eutopic endometrium.

\section{Theory of coelomic metaplasia}

Another theory states that peritoneal epithelium can be "transformed" into endometrial tissue, perhaps because of chronic inflammation or chemical irritation from refluxed menstrual blood. This theory of "coelomic metaplasia" is based on the observation that coelomic epithelium is the common ancestor of endometrial and peritoneal cells, thus allowing transformation of one type of cell into another.

\section{The embryonic rests theory}

A final theory hypothesizes that müllerian remnants can differentiate into endometrial tissue. The circumstances in which this would occur are not clear but, once endometrium is present, it will cause symptoms in a cyclic fashion.

Although retrograde menstruation seems almost certain to be involved in the pathogenesis of endometriosis, that theory does not explain the full spectrum of the disease. For example, endometrial implants are occasionally found in such remote sites as the lung or even the nose. Moreover, endometriosis also occurs, rarely, in men taking large doses of estrogen. The theories of coelomic metaplasia and müllerian remnant differentiation are better suited than the theory of retrograde menstruation to explain some of these exceptional circumstances. ${ }^{[14]}$ Porpora et al. evaluated the exposure to organ chlorinated persistent pollutants as a risk factor for endometriosis. They conducted a casecontrol study in Rome on 158 women comprising 80 cases and 78 controls. In all women, serum concentrations of selected non-dioxin-like PCBs (NDL-PCBs) and dioxin-like PCBs (DL-PCBs), 1,1-dichloro-2,2,-bis(4-chlorophenyl)ethane (p,p'-DDE), and hexachlorobenzene (HCB) were determined by ion-trap mass spectrometry. The results of this study show that an association exists between increased PCB and $p, p^{\prime}$-DDE serum concentrations and the risk of endometriosis. ${ }^{[15]}$ Rier has reviewed the available literature that provides evidence that dioxin and dioxin-like compounds are potent modulators of immune and endocrine function critical to the pathobiology of endometriosis. ${ }^{[16]}$ Chun-yan et al. have proposed that Annexin-1 is overexpressed in eutopic endometrium and presents in the peritoneal fluids of patients with endometriosis, and may play a role in the pathogenesis of endometriosis. ${ }^{[17]}$

Roya conducted a study to determine the possible association between polychlorinated biphenyls (PCBs) and GSTM1 null $(* 0 / * 0)$ mutation and their possible impact in the pathogenesis of endometriosis. Heparinized blood samples were collected from all for DNA isolation and estimation of PCBs. GSTM1 genotyping was done by PCR and PCBs were estimated by gas chromatography. Women with endometriosis showed significantly higher concentrations of PCBs compared with the control group. The study results suggested that women having higher concentration of PCBs and GSTM1 null $(* 0 / * 0)$ polymorphism might have an increased susceptibility of endometriosis. ${ }^{[18]}$

\section{Clinical features and diagnosis}

Endometriosis should be considered in any woman of reproductive age who has pelvic pain. The most common symptoms are dysmenorrhea, dyspareunia, and lower back pain that worsens during menses. ${ }^{[19]}$ Depending on the location of the implants, rectal pain and painful defecation may also occur. The diagnosis of endometriosis should be considered especially if a patient develops dysmenorrhea after years of pain-free menstrual cycles. Infertility may also be the presenting complaint. Infertile patients often have no painful symptoms, and their disease is only discovered in the course of the diagnostic work-up for infertility. The reason for this divergence in clinical manifestations is unknown. ${ }^{[14]}$

Physical examination should be performed during early menses, when implants are likely to be largest and most 
tender. The physician should palpate for a fixed, retroverted uterus, adnexal and uterine tenderness, pelvic masses, or nodularity along the uterosacral ligaments. A rectovaginal examination is required to identify uterosacral, culde-sac, or septal nodules. However, most women with endometriosis have normal pelvic findings, and laparoscopy is necessary for definitive diagnosis. Although no single laboratory test has shown reliable clinical utility, it is possible that eventually a combination of biochemical markers and clinical assessment will decrease the need for surgical confirmation. ${ }^{[20,21]}$ Pelvic ultrasonography, computed tomography, and magnetic resonance imaging are occasionally used to identify individual lesions, but these modalities are not helpful in assessing the extent of endometriosis. ${ }^{[2]}$

A study was done with the aim to determine the frequency of p53 codon 72 polymorphism in patients with endometriosis. It was found that the p53 polymorphism could be used as a molecular marker for endometriosis associated with exacerbated symptoms and infertility, and therefore as a great aid in the diagnosis of endometriosis, guiding prognosis, and treatment of this disease. ${ }^{[23]}$

\section{Staging of endometriosis}

Staging the disorder helps physicians formulate a treatment plan and evaluate response to therapy. According to the American Society for Reproductive Medicine, endometriosis may be classified as stage I (minimal), II (mild), III (moderate), or IV (severe), based on number, location, and depth of implants and presence of filmy or dense adhesions (Tables 1,2).

Another staging system is based primarily on the presence and severity of pelvic pain. However, because intraobserver and interobserver variability is high in the staging systems, a more reliable method of staging is being sought.

Antibodies against CD10 or common acute lymphoblastic leukemia antigen (CALLA) are now available for routine immunohistochemistry on paraffin wax-embedded tissues. CD10 is expressed by hematopoietic neoplasm's such as acute lymphoblastic leukemia and follicular lymphomas, and antibodies are widely used in lymphoma and leukemia panels. A recent study showed CD10 expression in a limited number of non-hematopoietic tissues, including normal endometrial stromal cells and endometrial stromal sarcoma. immunohistochemical staining with CD10 may be useful in identifying endometrial stroma (which otherwise lacks a characteristic immunohistochemical marker) and in confirming a diagnosis of endometriosis. Endometrial

\begin{tabular}{lll}
\hline Table & 1: Stages of endometriosis \\
\hline Stage & Disease & $\begin{array}{l}\text { Description } \\
\text { I }\end{array}$ \\
II & Minimal & A few superficial implants \\
III & Moderate & $\begin{array}{l}\text { More and slightly deeper implants } \\
\text { Many deep implants, small endometriomas on one or } \\
\text { both ovaries, and some filmy adhesions } \\
\text { Many deep implants, large endometriomas on one or } \\
\text { both ovaries, and many dense adhesions, sometimes } \\
\text { with the rectum adhering to the back of the uterus }\end{array}$ \\
\hline
\end{tabular}

\begin{tabular}{|c|c|c|c|c|}
\hline \multirow[t]{3}{*}{ Peritoneum } & Endometriosis & $<1 \mathrm{~cm}$ & $1-3 \mathrm{~cm}$ & $>3 \mathrm{~cm}$ \\
\hline & Superficial & 1 & 2 & 4 \\
\hline & Deep & 2 & 4 & 6 \\
\hline \multirow[t]{5}{*}{ Ovary } & Rt superficial & 1 & 2 & 4 \\
\hline & Deep & 4 & 16 & 20 \\
\hline & Lt superficial & 1 & 2 & 4 \\
\hline & Deep & 4 & 16 & 20 \\
\hline & \multicolumn{2}{|c|}{ Posterior cul-de-sac obliteration } & \multicolumn{2}{|c|}{ Partial complete 440} \\
\hline \multirow[t]{5}{*}{ Ovary } & Adhesions & $\begin{array}{c}<1 / 3 \\
\text { enclosure }\end{array}$ & $\begin{array}{c}1 / 3-2 / 3 \text { enc } \\
\text { losure }\end{array}$ & $\begin{array}{c}>2 / 3 \\
\text { enclosure }\end{array}$ \\
\hline & Rt filmy & 1 & 2 & 4 \\
\hline & Dense & 4 & 8 & 16 \\
\hline & Lt filmy & 1 & 2 & 4 \\
\hline & Dense & 4 & 8 & 16 \\
\hline \multirow[t]{4}{*}{ Tube } & Rt filmy & 1 & 2 & 4 \\
\hline & Dense & 41 & 81 & 16 \\
\hline & Lt filmy & 1 & 2 & 4 \\
\hline & Dense & 41 & 81 & 16 \\
\hline
\end{tabular}

${ }^{1}$ If the fimbriated end of the fallopian tube is completely enclosed, change the point assignment to 16 . Staging: Stage I (minimal): $1-5 ;$ stage II (mild): 6-15; stage III (moderate): 16-40; stage IV (severe): > 40

tissue in ectopic sites is almost invariably under the influence of ovarian hormones and therefore undergoes secondary changes such as bleeding and fibrosis. In those cases where endometrial-type glands and stroma are present, the histological diagnosis of endometriosis is often straightforward. However, especially in longstanding cases where the amount of endometrial stroma is sparse owing to fibrous obliteration, diagnosis becomes difficult. The distinction between non-specific fibrous stroma, ovarian stroma, and endometrial stroma can be difficult. In addition, in some cases, especially within the cervix, endometrial stroma may be present without glands, a condition known as stromal endometriosis. In these situations, examining multiple histological levels and performing CD10 immunohistochemistry may be extremely useful in confirming a diagnosis of endometriosis. In summary, analogous to the situation within the uterus, CD10 is a sensitive immunohistochemical marker of endometrial stromal cells at ectopic sites. In cases of suspected endometriosis where the reporting pathologist is unsure 
whether or not endometrial-type stroma is present, CD10 staining is of value in establishing a definitive diagnosis of endometriosis. ${ }^{[25]}$

\section{Molecular studies in endometriosis}

Kim et al examined the expression of HOXA10 in the eutopic endometrium of baboons with induced endometriosis. HOXA10 is one member of the homeobox gene family that plays a

fundamental role in development. A decrease in HOXA10 mRNA was observed after 3, 6, 12, and 16 months of disease, which reached statistical significance at 12 and 16 months. HOXA10 protein levels were decreased in both the epithelial and stromal cells of the endometrium. Furthermore, expression of b3 integrin (ITGB3), which is upregulated by HOXA10, was decreased, whereas EMX2, a gene that is inhibited by HOXA10, was increased. Next, methylation patterns of the HOXA10 gene were analyzed in the diseased and control animals. The F1 region on the promoter was found to be the most significantly methylated in the endometriosis animals and this may account for the decrease in HOXA10 expression. Stromal cells from the eutopic endometrium of baboons with endometriosis expressed significantly higher levels of insulin-like growth factor binding protein-1 (IGFBP1) mRNA than diseasefree animals in response to estradiol, medroxyprogesterone acetate and dibutyryl cAMP (H1dbcAMP). The functional role of HOXA10 in IGFBP1 expression was further explored using human endometrial stromal cells (HSC). Overexpression of HOXA10 in HSC resulted in a decrease of IGFBP1 mRNA, whereas silencing HOXA10 caused an increase of IGFBP1 mRNA, even in the presence of H1dbcAMP. These data demonstrate that HOXA10 negatively influences IGFBP1 expression in decidualizing cells. Thus, the decrease in HOXA10 levels may in part be involved with the altered uterine environment associated with endometriosis. ${ }^{[2]}$

Chun-Yan examined the expression of Annexin-1 in eutopic endometrium of women with or without endometriosis, and detected its expression in peritoneal fluids of those with endometriosis. Immunohistochemistry showed that Annexin-1 protein was expressed mainly in endometrial glandular cells throughout the menstrual cycle. Annexin-1 protein was detected in the peritoneal fluids of patients with endometriosis. He concluded that Annexin-1 is overexpressed in eutopic endometrium and presents in the peritoneal fluids of patients with endometriosis, and may play a role in the pathogenesis of endometriosis. ${ }^{[27]}$
Matsuzaki et al showed that platelet-derived growth factor receptor alpha (PDGFRA), protein kinase C beta1 (PKC beta1), and janus kinase 1 (JAK1) were upregulated, and Sprouty 2 and mitogen-activated protein kinase kinase 7 (MKK7) were downregulated in endometriosis stromal cells, suggesting the involvement of the RAS/ RAF/MAPK signaling pathway through PDGFRA in endometriosis pathophysiology. In addition, two potential negative regulators of aromatase expression, chicken ovalbumin upstream promoter transcription factor 2 (COUP-TF2) and prostaglandin E2 receptor subtype EP3 (PGE2EP3), were downregulated in endometriosis epithelial cells, which might result in increased local production of estrogen in endometriosis epithelial cells. Furthermore, three potential candidate genes that might be involved in endometriosis-related pain were identified: tyrosine kinase receptor $\mathrm{B}(\mathrm{TRkB})$ in endometriosis epithelial cells, and serotonin transporter (5HTT) and $\mathrm{mu}$ opioid receptor (MOR) in endometriosis stromal cells were all upregulated. One of the candidate genes, MOR, may be involved in a defective immune system in endometriosis. This study has provided new insights into endometriosis pathophysiology. ${ }^{[28]}$

The transcription factor nuclear factor-kappa B (NF-kB) activates proinflammatory, proliferative, and antiapoptotic genes in many cell types. To determine whether NF-kB is activated in peritoneal endometriosis in women, and further ascertain the differential inflammatory status of endometriotic implants, NF-kB activation and intercellular adhesion molecule (ICAM)-1 expression were investigated in peritoneal endometriotic lesions according to their type. Furthermore, p65 and p50 subunits of active NF-kB dimers were evaluated in endometriotic lesions to gain some insight into NF-kB-implicated pathways.

Constitutive NF-kB activation, involving p65- and p50-containing dimers, was demonstrated in peritoneal endometriotic lesions by electrophoretic mobility shift assays and supershift analyses, as well as NF-kB (p65) DNA-binding activity immunodetection assays.

This study demonstrated constitutive NF-kB activation in peritoneal endometriosis in women. The involvement of p50/p65 dimers in NF-kB activation suggests implication of the classic NF-kB activation pathway, making it an attractive therapeutic target in endometriosis. ${ }^{[2]}$

\section{Morphology}

Endometriosis typically appears as superficial "powder burn" or "gunshot" lesions on the ovaries, serosal surfaces 
and peritoneum-black, dark-brown, or bluish puckered lesions, nodules or small cysts containing old hemorrhage surrounded by a variable extent of fibrosis. Atypical or 'subtle' lesions are also common, including red implants (petechial, vesicular, polypoid, hemorrhagic, red flame-like) and serous or clear vesicles. Other appearances include white plaques or scarring and yellowish brown peritoneal discoloration of the peritoneum. Endometriomas usually contain thick fluid like tar; such cysts are often densely adherent to the peritoneum of the ovarian fossa and the surrounding fibrosis may involve the tubes and bowel. Deeply infiltrating endometriotic nodules extend $>5 \mathrm{~mm}$ beneath the peritoneum and may involve the uterosacral ligaments, vagina, bowel, bladder, or ureters. The depth of infiltration is related to the type and severity of symptoms. ${ }^{[30]}$

\section{Endometriosis in various sites}

\section{Cutaneous endometriosis}

Endometriosis occurring in a post-operative scar is a rare condition. ${ }^{[31]}$ The first case was reported by Meyer in $1903^{[32]}$ and since then there have been other reports of a few cases. $^{[32,33]}$

Chatzikokkinou et al have described the case of a 46-year-old woman who presented with a cutaneous black mass in the umbilicus. The histological analyses revealed that it consisted of endometrial tissue. There was no recurrence at 18-month follow-up. Endometriosis of the umbilicus is a rare condition and the pathogenesis is not completely elucidated. According to one theory, intraperitoneal endometrial tissue is translocated during endoscopic surgery or other surgical procedures that involve the umbilicus. However, in this case there was no history of abdominal wall surgery. They concluded that endometriosis is important to consider in cases of unclear skin lesions of the umbilicus, even in cases with no previous abdominal surgery. Moreover, umbilical endometriosis of the skin can have different appearances that resemble malignant tumors, and radical surgery with histology is therefore indicated. ${ }^{[34]}$ Three patients presented with primary isolated spontaneous umbilical endometriosis. One of them was having co-incidentally autosomal dominant polycystic disease of liver and kidneys. Another one was never pregnant and never had pelvic surgery which is very rare. ${ }^{[35]}$ Razzi et al report a case of umbilical endometriosis in a pregnant woman at 16 weeks of gestation. ${ }^{[36]}$

\section{Genitourinary tract endometriosis}

Involvement of the genitourinary tract has been reported at an incidence of between $0.01 \%$ and $1.2 \%$. The ratio of bladder-to-ureteral-to-renal involvement is 40:5:1 $1^{[37,38]}$ Two cases have been reported of ureteral endometriosis presenting as hydroureteronephrosis. ${ }^{[39,40]}$ Chen et al have reported a case of vesical endometriosis. ${ }^{[41]}$

\section{Fallopian tube endometriosis}

Yamamoto et al have described the presence of tubal endometriosis in a 13-year-old girl within 1 month after menarche. Endometriosis occurring shortly after menarche has been frequently reported and it is not always associated with mullerian anomalies which cause outflow obstruction. ${ }^{[42]}$ Schifrin et al reported 15 cases of adolescent endometriosis. ${ }^{[43]}$ Ambekar et al have described two cases to support the theory of origin of such a lesion from the fallopian tubal mucosa following salpingectomy. ${ }^{[44]}$ Harmanli et al have reported an unusual case of massive hemoperitoneum that led to preshock as a result of bleeding from a tubal endometriosis implant in a previously healthy 29 -year-old woman without previous history suggesting endometriosis. ${ }^{[5]}$ Idrees has reported the case of a 41-year-old woman with prior history of breast carcinoma who underwent bilateral salpingo-oophorectomy because of hematosalpinx. The histology revealed xanthogranulomatous salpingitis in the setting of extensive fallopian tube mucosal endometriosis, endometritis. ${ }^{[46]}$ Torre $e t$ al have described a rare case of clear cell carcinoma of the fallopian tubes associated with tubal endometriosis. ${ }^{[4]}$

\section{Gastrointestinal tract}

Endometriotic implants of the gastrointestinal tract are estimated to occur in $12-37 \%$ of patients with endometriosis. ${ }^{[48]}$ It most commonly affects those segments of bowel in the dependent portion of the pelvis and is rarely found proximal to the terminal ileum. ${ }^{[49]}$ The most commonly affected areas in decreasing order of frequency are the rectosigmoid colon, appendix, cecum, and distal ileum. ${ }^{[49,50]}$ The implants are usually serosal but can eventually erode through the subserosal layers and cause marked thickening and fibrosis of the muscularis propria. An intact overlying mucosa is almost always present, since the implanted tissue only rarely invades through to the mucosa. ${ }^{[4]}$ Inflammatory response to cyclic hemorrhage can lead to adhesions, bowel stricture, and gastrointestinal obstruction.

Oulaqi et al have reported the case of a 25-year-old woman who was admitted with a diagnosis of acute appendicitis associated with primary infertility. Histopathological examination of the appendix revealed endometriosis. ${ }^{[51]}$ The prevalence of appendiceal endometriosis is $2.8 \%{ }^{[52]}$ 
Involvement of the appendix may present as appendicitis, mucocele of appendix, or appendicular mass that may mimic a neoplasm. Perforation of the appendix may occur especially during the first two trimesters of pregnancy ${ }^{[5,54]}$ Cheong has described the case of endometriosis presenting as massive ascitis. ${ }^{[5]}$

Goldsmith et al report a case of hepatic endometriosis in a postmenopausal woman who presented with right upper quadrant pain as her only symptom. ${ }^{[56]}$ There have only been 11 previously reported cases of hepatic endometrioma. ${ }^{[57-64]}$ We found many case reports of scar endometriosis, in the abdominal wall following cesarean section. ${ }^{[65-70]}$ Lee reviewed the clinicopathologic findings of 18 samples from 15 patients with intestinal endometriosis. Three cases were associated with adenocarcinoma in the same or different segments; specifically, two primary rectal adenocarcinomas and one endometrioid adenocarcinoma arising from endometriosis. ${ }^{[71]}$

\section{Endometriosis and malignancy}

Malignant transformation is a well-described, although rare ( $<1 \%$ of cases), complication of endometriosis. Approximately $75 \%$ of these tumors arise from endometriosis of the ovary. ${ }^{[48]}$ Other less common sites include the rectovaginal septum, rectum, and sigmoid colon. Unopposed estrogen therapy may play a role in the development of such tumors ${ }^{[48,72]}$ Endometrioid carcinoma is the most common malignant neoplasm arising from endometriosis followed by clear cell carcinoma. ${ }^{[73,74]}$ Even when direct transition from endometriosis is not visualized, there is a definite association of both of these tumors with coexistent endometriosis. ${ }^{[49]}$ Large lesions and those with solid components suggest malignancy and must be removed. The criteria for diagnosis of a malignancy arising in endometriosis are (1) demonstration of a clear example of the endometriosis in proximity to the tumor, (2) no other primary site for the tumor, and (3) histologic appearance consistent with an origin from endometriosis. ${ }^{[7]}$ A case of Endometrial stromal sarcoma patient with extrauterine endometriosis has been reported. ${ }^{[76]}$ A survey of 45 extragonadal malignancies associated with endometriosis in 1977 found that $16(36 \%)$ were in the rectovaginal area, 5 $(11 \%)$ in the colorectal area, $4(9 \%)$ each in the bladder and vagina, $3(7 \%)$ in the pelvic ligaments, and $2(4 \%)$ each in the umbilicus, cervix, and fallopian tube. ${ }^{[77]} \mathrm{A}$ more recent survey of 27 malignancies associated with endometriosis found that $17(62 \%)$ were in the ovary, $3(11 \%)$ in the vagina, $2(7 \%)$ each in the fallopian tube or mesosalpinx, pelvic sidewall, and colon, and $1(4 \%)$ in the parametrium; ${ }^{[78]}$ this report, however, did not include cervical malignancies associated with endometriosis. Malignant transformation of extra-ovarian endometriosis is thought to account for approximately $25 \%$ of all malignant transformations of endometriosis. ${ }^{[79]}$ Park et al describe a woman with endometrioid adenocarcinoma arising from endometriosis of the uterine cervix. ${ }^{[80]}$

\section{Thoracic endometriosis}

There are three main theories of pathogenesis for thoracic endometriosis. ${ }^{[81-84]}$ Sampson theorized that menstrual blood with endometrial fragments could regurgitate from fallopian tube into peritoneal cavity. This blood could find its way to the subphrenic space and pass through the diaphragmatic fenestrations to the pleural cavity. Ivanoff theorized that irritant blood with endometrial fragments could pass through such fenestrations and produce metaplasia of pleural surface which is histologically similar to that of peritoneum. However these two theories do not explain parenchymal disease. Some theorize that obstetrical and gynecological procedures that disrupt endometrial blood vessels and lymphatics may allow lymphovascular entry of endometrial tissue causing parenchymal disease. This observation is linked with common association of pulmonary endometriosis and certain forms of endometrial trauma. A presumptive diagnosis of pulmonary endometriosis can be made with a typical clinical history. Yusuf reports a case of pleural endometriosis in a 28 years infertile lady who presented with catamenial hemothorax occurring in the first 3 days of menstruation over a 3 months period associated with right shoulder pain and progressive shortness of breath for last 6 years. ${ }^{[85]}$ Agrawal has reported the case of a 47-year-old woman who had undergone hysterectomy and bilateral salpingo-oophorectomy for endometriosis and presented 4 years after surgery with a well-differentiated endometrioid adenocarcinoma arising in the background of endometriosis in the right chest wall. ${ }^{[86]}$

\section{Endometriosis in extremeties}

The occurrence of endometriosis in areas other than the abdomen and pelvis is uncommon, and in the extremities it is rare. The case of a patient who had endometriosis in the body of the biceps femoris has been described. ${ }^{[87]}$ In 1982, Patel et al described the case of a patient who had endometriosis on the lateral aspect of the knee behind the fibular head, and under the lateral head of the gastrocnemius muscle. In a patient whose case was described by Vaisberg, the tumor was located in the fascia between the hamstring muscles and caused sciatica. However, in the lower extremity, the most common sites 
of endometriosis appear to be the inguinal region and the thigh. ${ }^{[88]}$ When the lesions are found in the groin or in the anterior or anteromedial aspect of the thigh, the cells have presumably followed the course of the round ligament through the inguinal canal.

\section{CNS endometriosis}

Central nervous system involvement is rare. ${ }^{[89,90]}$ Sarma et al describe a cystic mass involving the cerebellar vermis, with MRI features of intracystic hemorrhage similar to that described in pelvic endometriomas. ${ }^{\left[{ }^{[1]}\right.}$ Only two previous case reports of cerebral endometriosis are found in the English-language literature. ${ }^{[22,93]}$

\section{Complications of endometriosis}

Complications of endometriosis include the following

- The bleeding can form bands of scar tissue (adhesions) that can attach to the organs in the pelvis and abdomen.

- Reduced fertility that may have no obvious cause or may be caused by adhesions forming on or near to your ovaries or fallopian tubes.

- An increased risk of miscarriage or giving birth prematurely.

- Cysts can bleed or rupture, causing severe pain.

- Endometriosis of the intestine can cause the bowel to become blocked or twisted.

- An increased risk of certain types of cancer, particularly ovarian.

\section{Treatment}

Treatment for endometriosis can be expectant, medical, or surgical, depending on the severity of symptoms and the patient's desire to maintain or restore fertility. ${ }^{[04,95]}$ Because no pharmacologic method has been proved to restore fertility, patients with infertility secondary to endometriosis are usually treated surgically or with advanced reproductive techniques. Medical treatment is used for patients with pelvic pain or dyspareunia. Medical treatment strategies focus on hormonal manipulation of the menstrual cycle to create states of pseudopregnancy, pseudomenopause, or chronic anovulation. Frequently prescribed agents include Danazol, gonadotropinreleasing hormone agonists, oral contraceptive pills, and other progestational agents. Conservative surgery can be performed with laparoscopy or laparotomy. Success rates are believed to be high, but implant recurrence develops in $28 \%$ of patients at 18 months after surgery and in $40 \%$ by 9 years ${ }^{[0,97]}$ Adhesions recur in $40-50 \%$ of patients. ${ }^{[98]}$ Women with infertility and endometriosis may be treated with advanced reproductive techniques such as ovarian hyperstimulation and intrauterine insemination and have monthly fecundity rates of $9-18 \% \cdot{ }^{[99,100]}$ Definitive surgery includes hysterectomy and oophorectomy and is usually reserved for women with intractable pain. ${ }^{[101]}$ In less severe cases, one ovary may be retained. Endometriosis may recur with exogenous estrogen replacement therapy, even in women who have undergone oophorectomy. ${ }^{[101]}$ Koninckx conducted the first randomized, placebo-controlled trial to assess the effect of an anti-TNF- $\alpha$ a drug in the treatment of deep endometriosis-associated pain. He found that infliximab appears to have no important beneficial effect upon pain associated with deep endometriosis. ${ }^{[102]}$

\section{REFERENCES}

1. Jansen RP, Russell P. Nonpigmented endometriosis: clinical, laparoscopic, and pathologic definition. Am J Obstet Gynecol 1986;155:1154-9.

2. Heaps JM, Nieberg RK, Berek JS. Malignant neoplasms arising in endometriosis. Obstet Gynecol 1990;75:1023-8.

3. Olive DL, Henderson DY. Endometriosis and mullerian anomalies. Obstet Gynecol 1987;69:412-5.

4. Matorras R, Rodríguez F, Pijoan JI, Soto E, Pérez C, Ramón O, et al. Are there any clinical signs and symptoms that are related to endometriosis in infertile women? Am J Obstet Gynecol 1996;174:620-3.

5. Dmowski WP, Lesniewicz R, Rana N, Pepping P, Noursalehi M. Changing trends in the diagnosis of endometriosis: a comparative study of women with pelvic endometriosis presenting with chronic pelvic pain or infertility. Fertil Steril 1997;67:238-43.

6. Goldstein DP, deCholnoky C, Emans SJ, Leventhal JM. Laparoscopy in the diagnosis and management of pelvic pain in adolescents. J Reprod Med 1989;24:251-6.

7. Chatman DL, Ward AB. Endometriosis in adolescents. J Reprod Med 1982;27:156-60.

8. Huffman JW. Endometriosis in young teen-age girls. Pediatr Ann 1981; 10:44-9.

9. Clement PB. Pathology of endometriosis. Pathol Annu 1990;25:245-95.

10. Eskenazi B, Warner ML. Epidemiology of endometriosis. Obstet Gynecol Clin North Am 1997;24:235-58.

11. Olive DL, Schwartz LB. Endometriosis. N Engl J Med 1993;328:1759-69.

12. Lu PY, Ory SJ. Endometriosis: current management. Mayo Clin Proc1995; 70:453-463.

13. Story L, Kennedy S. Animal studies in endometriosis: a review. ILAR J 2004;45:132-8.

14. Wellbery C. Diagnosis and treatment of endometriosis. Am Fam Physician 1999;60:1753-68.

15. Porpora MG, Medda E, Abballe A, Bolli S, De Angelis I, di Domenico A, et al. Endometriosis and organochlorinated environmental pollutants: a case-control study on Italian women of reproductive age. Environ Health Perspect 2009;117:1070-75.

16. Rier S, Foster WG. Environmental dioxins and endometriosis. Toxicol Sci 2002;70:161-70.

17. Li CY, Lang JH, Liu HY, Zhou HM. Expression of Annexin-1 in patients with endometriosis. Chin Med J 2008;121:927-31.

18. Roya R, Baludu GS, Reddy BS. Possible aggravating impact of gene polymorphism in women with endometriosis. Indian J Med Res 2009;129:395-400.

19. American College of Obstetricians and Gynecologists. Endometriosis. ACOG technical bulletin no. 184. Washington DC: ACOG; 1993.

20. Medl M, Ogris E, Peters-Engl C, Mierau M, Buxbaum P, Leodolter S. Serum levels of the tumour-associated trypsin inhibitor in patients with 


\section{Agarwal and Subramanian: Endometriosis}

endometriosis. Br J Obstet Gynaecol 1997;104:78-81.

21. Brinton DA, Quattrociocchi-Longe TM, Kiechle FL. Endometriosis: identification by carbonic anhydrase autoantibodies and clinical features. Ann Clin Lab Sci 1996;26:409-20.

22. Olive DL, Schwartz LB. Endometriosis. N Engl J Med 1993;328:1759-69.

23. Ribeiro Júnior CL, Arruda JT, Silva CT, Moura KK. Analysis of p53 codon 72 gene polymorphism in Brazilian patients with endometriosis. Genet Mol Res 2009;8:494-9.

24. American society for reproductive medicine(ASRM)(1997)Revised American society for reproductive medicine classification of endometriosis 1996. Fertil Steril 67,817-821.

25. Sumathi VP, McCluggage WG. CD10 is useful in demonstrating endometrial stroma at ectopic sites and in confirming a diagnosis of endometriosis. J Clin Pathol 2002;55:391-92.

26. Kim JJ, Taylor HS, Lu Z, Ladhani O, Hastings JM, Jackson KS, et al. Altered expression of HOXA10 in endometriosis: potential role in decidualization. Mol Hum Reprod 2007;13:323-32.

27. Li CY, Lang JH, Liu HY, Zhou HM. Expression of Annexin-1 in patients with endometriosis. Chin Med J 2008;121:927-31.

28. Matsuzaki S, Canis M, Vaurs-Barrière C, Pouly JL, Boespflug-Tanguy O, Penault-Llorca F, et al. DNA microarray analysis of gene expression profiles in deep endometriosis using laser capture microdissection. Mol Hum Reprod 2004;10:719-28.

29. González-Ramos R, Donnez J, Defrère S, Leclercq I, Squifflet J, Lousse JC, et al. Nuclear factor-kappa B is constitutively activated in peritoneal endometriosis. Mol Hum Reprod 2007;13:503-9.

30. Kennedy S, Bergqvist A, Chapron C, D'Hooghe T, Dunselman G, Greb R, et al. ESHRE guideline for the diagnosis and treatment of endometriosis. Hum Reprod 2005;20:2698-704.

31. Henriksen E. Endometriosis. Am J Surg 1955;90:331-37.

32. Wyrens RG, Randall LM. Endometriosis in scars. Am J Surg 1942;56:397-403.

33. Meigs JV. An Interest In Endometriosis And Its Consequences. Am J Obst Gynaec 1960;79:625-35.

34. Chatzikokkinou P, Thorfinn J, Angelidis K I, Papa G, Trevisan G. Spontaneous endometriosis in an umbilical skin lesion. Acta Dermatoven APA 2008;18:126-30.

35. Saad Suhair Al, Malik Hamdi Mohammed Al-Shinawi, Kumar A, Amallia F.I.Brair. Extra-Gonadal Endometriosis: Unusual Presentation. Bahrain Medical Bulletin; 2007;29:1-11.

36. Razzi S, Rubegni P, Sartini A, De Simone S, Fava A, Cobellis L, et al. Umbilical endometriosis in pregnancy: a case report. Gynecol Endocrinol 2004;18:114-6.

37. Stillwell TJ, Kramer SA, Lee RA. Endometriosis of ureter. Urology 1986;28:81-5.

38. Jubanyik KJ, Comite F. Extrapelvic endometriosis. Obstet Gynecol Clin North Am 1997;24:411-40.

39. Kondo T. Ureteral polypoid endometriosis causing hydroureteronephrosis. Indian J Pathol Microbiol 2009;52:246-8.

40. Chen Chien-Hua, Hsieh Teh-Sheng, Lin Chih-Min. Ureteral Endometriosis with Renal Loss: A Case Report. JTUA 2004;15:185-9.

41. Chen Wen-Ming, Yang Chi-Rei, Cheng Chen-Li, Ou Yen-Chuan, Ho Hao-Chung. Vesical Endometriosis: A Case Report. JTUA 2003;14:183-6.

42. Yamamoto K, Mitsuhashi Y, Takaike T, Takase K, Hoshiai H, Noda K. Tubal endometriosis diagnosed within one month after menarche: a case report. Tohoku J Exp Med 1997;181:385-7.

43. Schifrin BS, Erez S, Moore JG. Teen-age endometriosis. Am J Obstet Gynecol 1973;116:973-80.

44. Ambekar SV, Mudbhatkal NS, Kothare SN. Post-salpingectomy endometriosis (endosalpingiosis); a report of two cases. J Postgrad Med 1964;11:141-4.

45. Harmanli OH, Chatwani A, Caya JG. Massive hemoperitoneum from endometriosis of the fallopian tube. A case report. J Reprod Med 1998;43:716-8

46. Idrees M, Zakashansky K, Kalir T. Xanthogranulomatous salpingitis associated with fallopian tube mucosal endometriosis: a clue to the pathogenesis. Ann Diagn Pathol 2007;11:117-21.
47. de la Torre FJ, Rojo F, García A. Clear cells carcinoma of fallopian tubes associated with tubal endometriosis. Case report and review. Arch Gynecol Obstet 2002;266:172-4.

48. Clement PB. Diseases of the peritoneum. In: Kurman RJ, editors. Blaustein's pathology of the female genital tract. $4^{\text {th }}$ ed. New York: Springer-Verlag; 1994. P. 660-80.

49. Gedgaudas-McClees RK. Gastrointestinal complications of gynecologic diseases In: Textbook of gastrointestinal radiology. Philadelphia: Saunders; 1994. P. 2559-67.

50. Zwas FR, Lyon DT. Endometriosis. An important condition in clinical gastroenterology. Dig Dis Sci 1991;36:353-64.

51. Al Oulaqi NS, Hefny AF, Joshi S, Salim K, Abu-Zidan FM. Endometriosis of the appendix. Afr Health Sci 2008;8:196-8.

52. Gustofson RL, Kim N, Liu S, Stratton P. Endometriosis and the appendix: a case series and comprehensive review of the literature. Fertil Steril 2006;86:298-303.

53. Yantiss RK, Clement PB, Young RH. Endometriosis of the intestinal tract: a study of 44 cases of a disease that may cause diverse challenges in clinical and pathologic evaluation. Am J Surg Pathol 2001;25:445-54.

54. Driman DK, Melega DE, Vilos GA, Plewes EA. Mucocele of the appendix secondary to endometriosis. Report of two cases, one with localized pseudomyxoma peritonei. Am J Clin Pathol 2000;113:860-4.

55. Cheong EC, Lim DT. Massive ascites-an uncommon presentation of endometriosis. Singapore Med J 2003;44:98-100.

56. Goldsmith PJ, Ahmad N, Dasgupta D, Campbell J, Guthrie JA, Lodge JP. Case hepatic endometriosis: a continuing diagnostic dilemma. HPB Surg 2009;2009:407206.

57. Finkel L, Marchevsky A, Cohen B. Endometrial cyst of the liver. Am J Gastroenterol 1986;81:576-8.

58. Rovati V, Faleschini E, Vercellini P, Nervetti G, Tagliabue G, Benzi G Endometrioma of the liver. Am J Obstet Gynecol 1990;163:1490-2.

59. Grabb A, Carr L, Goodman JD, Mendelson DS, Cohen B, Finkel L. Hepatic endometrioma. J Clin Ultrasound 1986;14:478-80.

60. Verbeke C, Härle M, Sturm J. Cystic endometriosis of the upper abdominal organs. Report on three cases and review of the literature. Pathol Res Pract 1996;192:300-04

61. Cravello L, D'Ercole C, Le Treut YP, Blanc B. Hepatic endometriosis: a case report. Fertil Steril 1996;66:657-9.

62. Chung CC, Liew CT, Hewitt PM, Leung KL, Lau WY. Endometriosis of the liver. Surgery 1998;123:106-8.

63. Inal M, Biçakçi K, Soyupak S, Oğuz M, Ozer C, Demirbaş O, et al. Hepatic endometrioma: a case report and review of the literature. Eur Radiol 2000;10:431-4.

64. Huang WT, Chen WJ, Chen CL, Cheng YF, Wang JH, Eng HL. Endometrial cyst of the liver: a case report and review of the literature. J Clin Pathol 2002;55:715-7.

65. Emine Dundar, Haluk K_Per, Kismet B_LD_R_C, Bahattin Erdogan, Mehmet Aksoy, Endometriosis in obliquus externus abdominis muscle: A case report and review of the literature. Erciyes Tip Dergisi 2002;24:153-6.

66. Kilin N, Mehmet Ahmet Yalinkaya, Nondecidualized Zaydin, Decidualized Endometriosis of the Abdominal Wall (A Report of Two Cases Secondary to Cesarean Section). Turk J Med Sci 2002;32:505-8.

67. Chatterjee SK. Scar endometriosis: a clinicopathologic study of 17 cases Obstet Gynecol 1980;56:81-4.

68. Bottino G, Marinello M, Menna C, Torchio B, Vergano R. Endometriosis of the lower abdominal wall. Report of two cases secondary to cesarean section. Minerva Ginecol 1990;42:283-5.

69. Koger KE, Shatney CH, Hodge K, McClenathan JH. Surgical scar endometrioma. Surg Gynecol Obstet 1993;177:243-6.

70. Daye SS, Barone JE, Lincer RM, Blabey RC, Smego DR. Pfannenstiel syndrome. Am Surg 1993;59:459-460.

71. Heejin Lee Kyu-Rae Kim. Intestinal Endometriosis: Clinicopathologic Analysis of 15 Cases Including a Case of Endometrioid Adenocarcinoma. The Korean Jrnl of Patho 2009;43:120-5.

72. Yantiss RK, Clement PB, Young RH. Neoplastic and pre-neoplastic changes in gastrointestinal endometriosis: a study of 17 cases. Am J Surg Pathol 2000;24:513-24.

Journal of Laboratory Physicians / Jan-Jun 2010 / Vol-2 / Issue-1 


\section{Agarwal and Subramanian: Endometriosis}

73. Scully RE, Young RH, Clement PB. Endometrioid tumors In: Tumors of the ovary, maldeveloped gonads, fallopian tube, and broad ligament. Washington DC: Armed Forces Institute of Pathology; 1998. p. 107-40.

74. Scully RE, Young RH, Clement PB. Clear cell tumors In: Tumors of the ovary, maldeveloped gonads, fallopian tube, and broad ligament. Washington DC: Armed Forces Institute of Pathology, 1998. p. 141-52.

75. Sampson J. Endometrial carcinoma of the ovary, arising in endometrial tissue in that organ. Arch Surg 1925;10:1-72.

76. Park Soo-Kyung. Lee Sun-Joo. Kwon Han Sung. Sohn In Sook, Lee Ji Young, Kim Soo Nyung, et al. Endometrial stromal sarcoma associated with extrauterine endometriosis: a case report and literature review. Kore J Gynecol Oncol 2008;19:87-92.

77. Brooks JJ, Wheeler JE. Malignancy arising in extragonadal endometriosis: a case report and summary of the world literature. Cancer 1977;40:3065-73.

78. Leiserowitz GS, Gumbs JL, Oi R, Dalrymple JL, Smith LH, Ryu J, et al. Endometriosis-related malignancies. Int J Gynecol Cancer 2003;13:466-71.

79. Modesitt SC, Tortolero-Luna G, Robinson JB, Gershenson DM, Wolf JK. Ovarian and extraovarian endometriosis-associated cancer. Obstet Gynecol 2002;100:788-95.

80. Park HM, Lee SS, Eom DW, Kang GH, Yi SW, Sohn WS. Endometrioid adenocarcinoma arising from endometriosis of the uterine cervix: a case report. J Korean Med Sci 2009;24:767-71.

81. Joseph J, Reed CE, Sahn SA. Thoracic endometriosis. Recurrence following hysterectomy with bilateral salpingo-oophorectomy and successful treatment with talc pleurodesis. Chest 1994;106:1894-96.

82. Lee CY, Di Loreto PC, Beaudoin J. Catamenial pneumothorax. Obstet Gynecol 1974;44:407-11.

83. Crosby DJ. Catamenial pneumothorax. Ariz Med 1973;30.260-61.

84. Hibbard LT, Schumann WR, Goldstein GE. Thoracic endometriosis: a review and report of two cases. Am J Obstet Gynecol 1981;140:227-32.

85. Yusuf N, Haque M A, Rahman M H, Ali M A. An Atypical Presentation of A Case of Endometriosis. TAJ 2006;19:27-30.

86. Agrawal A, Nation J, Ghatage P, Chu P, Ross S, Magliocco A. Malignant chest wall endometriosis: a case report and literature review. J Obstet Gynaecol Can 2009;31:538-41.

87. Giangarra C, Gallo G, Newman R, Dorfman H. Endometriosis in the biceps femoris. A case report and review of the literature. J Bone Joint Surg Am 1987;69:290-92.

88. Gitelis S, Petasnick JP, Turner DA, Ghiselli RW, Miller AW $3^{\text {rd }}$. Endometriosis simulating a soft tissue tumor of the thigh: CT and MR evaluation. J Comput Assist Tomogr 1985;9:573-6.
89. Child TJ, Tan SL. Endometriosis: aetiology, pathogenesis and treatment. Drugs 2001;61:1735-50.

90. Woodward PJ, Sohaey R, Mezzetti TP Jr. Endometriosis: radiologicpathologic correlation. Radiographics 2001;21:193-216.

91. Sarma D, Iyengar P, Marotta TR, terBrugge KG, Gentili F, Halliday W. Cerebellar endometriosis. AJR Am J Roentgenol 2004;182:1543-6.

92. Thibodeau LL, Prioleau GR, Manuelidis EE, Merino MJ, Heafner MD. Cerebral endometriosis. Case report. J Neurosurg 1987;66: 609-10.

93. Ichida M, Gomi A, Hiranouchi N, Fujimoto K, Suzuki K, Yoshida M, et al. A case of cerebral endometriosis causing catamenial epilepsy. Neurology 1993;43:2708-09.

94. Olive DL, Schwartz LB. Endometriosis. N Engl J Med 1993;328: 1759-69.

95. Wellbery C. Diagnosis and treatment of endometriosis. Am Fam Physician 1999;60:1753-68.

96. Gordts S, Boeckx W, Brosens I. Microsurgery of endometriosis in infertile patients. Fertil Steril 1984;42:520-25.

97. Olive DL. Conservative surgery. In: Schenken RS, editors.Endometriosis: contemporary concepts in clinical management. Philadelphia, Pa: Lippincott; 1989. P. 213-47.

98. Vancaillie T, Schenken RS. Endoscopic surgery. In: Schenken RS, editors. Endometriosis: contemporary concepts in clinical management. Philadelphia, Pa: Lippincott; 1989. p. 249-66.

99. Chaffkin LM, Nulsen JC, Luciano AA, Metzger DA. A comparative analysis of the cycle fecundity rates associated with combined human menopausal gonadotropin (hMG) and intrauterine insemination (IUI) versus either hMG or IUI alone. Fertil Steril 1991;55:252-7.

100. Dodson WC, Haney AF. Controlled ovarian hyperstimulation and intrauterine insemination for treatment of infertility. Fertil Steril 1991;55:457-67.

101. Namnoum AB, Hickman TN, Goodman SB, Gehlbach DL, Rock JA Incidence of symptom recurrence after hysterectomy for endometriosis. Fertil Steril 1995;64:898-902.

102. Koninckx PR, Craessaerts M, Timmerman D, Cornillie F, Kennedy S. AntiTNF-alpha treatment for deep endometriosis-associated pain: a randomized placebo-controlled trial. Hum Reprod 2008;23:2017-23.

Source of Support: Nil, Conflict of Interest: None declared 